\title{
Prospectando futuros para a educação superior no contexto pós-pandemia COVID-19
}

\section{Prospecting futures to university education in COVID-19 post- pandemic context}

\author{
Fernanda Botter, Universidade Tecnológica Federal do Paraná (UTFPR)
}

fernandabotter@utfpr.edu.br

\author{
Kando Fukushima, Universidade Tecnológica Federal do Paraná (UTFPR) \\ kandofukushima@utfpr.edu.br
}

\author{
Milena Maria Rodege Gogola, Universidade Tecnológica Federal do Paraná \\ (UTFPR) \\ milenamrg@gmail.com
}

\begin{abstract}
Resumo
Na expansão do espaço projetual do design para lidar com problemas sistêmicos se fundamenta a importância do Design Transicional e Prospectivo, abordagens que tratam de pensar e transformar a realidade, visando o longo prazo. Neste artigo discorreremos sobre como tais abordagens nos motivaram a investigar as nuances e impactos da crise sanitária da COVID-19, para propor um evento que visou instigar a comunidade acadêmica e externa à UTFPR a projetar futuros para a educação superior brasileira partir de seus possíveis desdobramentos. Este evento-piloto estimulou o debate sobre tensões e tendências tecnológicas presentes e futuras para a educação superior envolvendo, inclusive, atores inusitados. Os resultados revelam a grande validade do Design Prospectivo para abrir nossa visão acerca das possibilidades de ação da Universidade diante das restrições e mudanças emergenciais que a pandemia requer.
\end{abstract}

Palavras-chave: Design Prospectivo, Design de Transições, COVID-19, Educação superior

\begin{abstract}
The importance of Transition and Prospective Design - approaches that deal with thinking and transforming reality aiming long-term scenarios - is founded on the design space expansion to deal with systemic problems. In this paper, we discuss how such approaches motivated the metaproject of an event created to instigate the academic and general community to design future visions to Brazilian university education, considering the impacts of COVID-19 sanitary crisis. This pilot project stimulated the debate around present and future tensions and technological tendencies for university education in teams that included actors from multiple academic levels and specialties. Results reveal the potential of Prospective Design to open our perspective about the possibilities of action of the University in the face of the restrictions and emergency changes that the pandemic requires.
\end{abstract}

Keywords: Prospective Design, Transition Design, COVID-19, university education 


\section{Introdução}

A pandemia COVID-19 aprofundou problemas e falhas, e ressaltou tensões entre pessoas e instituições em todos os âmbitos dos nossos sistemas sócio-técnicos - o conjunto de artefatos, práticas, infraestruturas, redes, mercados, saberes que produzem e são produto de significados culturais (GEELS, 2005). Tais tensões e rupturas nos mostram a urgência de transformarmos nosso modo de vida.

Este artigo demonstra como as abordagens do Design de Transições e Prospectivo orientaram o projeto de um evento piloto, proposto por docentes do grupo de estudos e pesquisas em Design Prospectivo do Departamento Acadêmico de Desenho Industrial da Universidade Tecnológica Federal do Paraná (DADIN, UTFPR). O projeto da Prospectina começou com a problematização do impacto da pandemia na Universidade diante da ausência de um debate amplo e da falta de uma orientação clara do Ministério da Educação, que refletem, ainda que tacitamente, o projeto de futuro do Governo Federal para a educação superior. Observando as necessidades não atendidas trazidas à tona pela pandemia, a partir de uma visão prospectiva, desejamos mostrar que mudanças de longo prazo exigem visão sistêmica, já que a transformação planejada de realidades depende da problematização que antecede o projeto.

Baseamos o evento na dinâmica projetual chamada Repentina, prática projetual de brevíssima duração recorrente em eventos estudantis de design. Esperávamos que as propostas das equipes participantes funcionassem como um catalisador de ideias para iniciarmos a traçar um planejamento da transição para uma UTFPR que corresponda aos anseios do grupo, uma instituição mais humana, justa, igualitária, que celebre a diversidade, vise a sustentabilidade e a autonomia estudantil. Propusemos cenários futuros e questionamentos deles derivados para estimular as equipes participantes a visualizar e articular suas intervenções.

$\mathrm{Na}$ primeira parte deste artigo, discorremos sobre o que nos motivou a promover a repentina. No segundo capítulo, tratamos das quatro ordens do Design propostas por Richard Buchanan (2001) e da sua relação com os "problemas capciosos" descritos por Horst Rittel (RITTEL e WEBBER, 1973). Apresentamos um panorama da visão de Design Prospectivo, lançando mão dos estudos de Bridgitte Egeler (2017) e de Terry Irwin (2015), mas também de Boaventura de Sousa Santos $(1995,2019)$ e Arturo Escobar (2015) de modo a fornecer subsídios para responder à nossa pergunta de pesquisa: como as teorias do Design de Transições e Prospectivo nos orientaram a projetar um evento destinado a imaginar futuros para a educação na UTFPR no contexto da pandemia COVID-19? No terceiro capítulo discorremos acerca do projeto, e também sintetizamos as propostas entregues pelas equipes. No último, apresentamos as conclusões a respeito dos desdobramentos possíveis para este exercício criativo que gerou ricas discussões postas por grupos heterogêneos e interessados no futuro da educação superior brasileira. 


\section{Breve contextualização na instituição}

Embora a discussão sobre o uso de novas tecnologias seja um tema constante na pauta educacional (FEENBERG, 2015), a crise sanitária do COVID-19 destacou de maneira urgente as questões ligadas à implementação de modalidades de ensino não-presencial nos diversos níveis de educação formal. Durante o período 'Emergencial', alguns ajustes fundamentais foram apresentados através de resoluções do MEC, com consequências às práticas da educação superior.

Se alguns debates sobre o potencial de ampliação da capilaridade do ensino através do EaD (Ensino à Distância) e outras vantagens relacionadas à flexibilização eram recorrentes, a aparente imposição de um modelo similar de forma generalizada destacou suas limitações e a complexidade dos fatores envolvidos. Essas questões não se apresentaram apenas no debate das TIC (Tecnologias da Informação e Comunicação), ainda que fossem já bastante presentes anteriormente, mas também nas discussões sobre um cotidiano constantemente mediado por artefatos conectados digitalmente e suas implicações sociais, culturais, políticas e econômicas.

Uma das principais contradições suscitadas pela pandemia está ligada ao acesso amplo aos recursos digitais. Segundo o relatório da Associação Nacional dos Dirigentes das Instituições de Federais de Ensino Superior, cerca de 70\% dos estudantes das Instituições Federais de Ensino Superior são considerados de baixa renda (ANDIFES, 2019), e na UTFPR especificamente, cerca de $63 \%$. Esses dados estão diretamente relacionados à possibilidade dos estudantes continuarem seus estudos. Citando algumas das situações menos extremas, podemos mencionar as limitações dos planos de dados móveis e os ambientes e equipamentos inadequados para estudos. Os recursos das universidades para amparar ou mitigar alguns dos problemas identificados são um constante desafio.

$\mathrm{Na}$ instituição, a formação e prática dos docentes, na maioria dos casos, está ligada às interações presenciais, além do desenvolvimento de conhecimentos em ambientes como laboratórios e salas de aulas. Ainda que a necessidade de alguma adaptação decorrente do contexto seja urgente, a decisão pela adoção de uma, ou várias dentre as diversas possibilidades existentes, exige cautela e reflexão.

A normativa que instituiu as atividades didáticas não presenciais UTFPR, como foram chamadas na instituição ${ }^{1}$, depende, além desses aspectos mencionados, das próprias resoluções do MEC. Estas sofreram ajustes com implicações diretas na condução das atividades durante a pandemia, algumas delas envolvendo questões conceituais fundamentais, e não apenas adaptações em datas ou ajustes menores. Destacamos aqui a problemática das disciplinas ministradas em laboratórios de caráter prático: na portaria $\mathrm{n}^{\circ} 345$, de 19 de março de 2020 estava vetada a

1 Conforme Resolução $\mathrm{n}^{\mathrm{o}}$ 19/2020 - COGEP/UTFPR. Disponível em < http://portal.utfpr.edu.br/documentos/graduacao-e-educacao-profissional/prograd/diretrizese-regulamentos $>$. Acesso em 22 de julho de 2020. 
substituição de aulas de laboratório por meios remotos (artigo $1, \S 3^{\circ}$ ), limitação que foi revogada na portaria ${ }^{\circ} 544$ de 16 de junho de $2020^{2}$.

\section{Conceitos}

As Quatro Ordens do Design e os "problemas capciosos"

Localizamos em Richard Buchanan (2001) um conceito que busca identificar a ampliação do escopo das práticas de design ${ }^{3}$, apresentando uma proposta de sistematização desse cenário. $\mathrm{O}$ autor propõe uma tipificação dos projetos de design, sem abandonar características da abordagem tradicional, focada em artefatos e incremento de complexidade (gráfico, serviço, etc.). Define a disciplina do Design na contemporaneidade como a detentora de métodos e ferramentas cuja utilização pode questionar o paradigma da ciência dividida por especialidades, integrando conhecimentos de vários campos do saber para materializá-los em resultados produtivos.

Uma das bases desse viés é a relação com o conceito de wicked problems (problemas capciosos) na teoria do design, apontado originalmente por Horst Rittel ainda na Escola de Ulm nos anos 1960, e publicado de forma mais organizada em forma de artigo ${ }^{4}$ por Rittel e Melvin Webber (1973) em "Dilemmas in a general theory of planning", quando ele já lecionava na Universidade da Califórnia. Dentre os desdobramentos dessa teoria, podemos destacar o aspecto indeterminado desses problemas, seu caráter complexo e abrangente; o favorecimento do processo participativo, envolvendo pessoas afetadas pelo projeto; a crítica à linearidade pretendida na metodologia projetual; e o objetivo de alcançar um resultado cientificamente "verdadeiro" nas escolhas de design.

Rittel identifica no design uma atividade de planejamento e antecipação crítica com desdobramentos práticos, que envolve uma tomada de decisão ou escolha, defendendo uma abordagem que reconhece a indeterminação e a complexidade. Em seu texto "On the Planning Crisis" (RITTEL, 1972, p.394) afirma que o design no contexto dos "problemas capciosos" é sempre político. Este tipo de entendimento dos problemas de design é apresentado em contraposição aos tamed problems, os problemas "domesticados", mapeáveis com precisão, cujas soluções são do tipo certas ou erradas.

\footnotetext{
2 A portaria MEC $\mathrm{n}^{\mathrm{o}} 544$ de 16/06/2020 revoga as portarias do MEC $\mathrm{n}^{\circ} 343$, de 17/03/2020; $\mathrm{n}^{\mathrm{o}} 345$, de 19/03/2020; e no 473, de 12/05/2020. Disponível em <http://www.in.gov.br/en/web/dou/-/portaria-n-544de-16-de-junho-de-2020-261924872> Acesso em 22 de julho de 2020.

${ }^{3}$ A ampliação do escopo das práticas do design se relaciona diretamente à expansão do 'espaço projetual', ou seja, o domínio em que designers sentem-se aptos a atuar. É discutido por Gabriela Goldschmidt (1997), Kiss and Cross (2001), Chien and Flemming (2002), Westerlund (2005), Botero, Kommonen and Marttila (2010).

${ }^{4}$ Segundo Buchanan (1992, p.15) o termo já havia sido publicado em 1967, pelo filósofo Charles West Churchman, também professor da Universidade da Califórnia, referenciando Rittel.
} 
Levando em consideração essas aproximações teóricas, dentre as 4 Ordens de Buchanan (2001), na quarta ordem (sistemas e ambientes) a problemática da indeterminação e complexidade é mais evidente. Conforme a figura 1, a primeira ordem é destinada ao Design Gráfico, e se refere aos projetos para a comunicação através de símbolos, textos e imagens. A segunda trata do Design Industrial, que abarca a criação de artefatos físicos, como bens de consumo e produtos tipicamente associados à engenharia e à arquitetura. A terceira ordem contempla o Design de Interação, projetos de serviços e processos. Finalmente, a ordem do Design de Sistemas engloba todas as anteriores, buscando seus fundamentos nas relações sistêmicas entre artefatos, ambientes e pessoas.

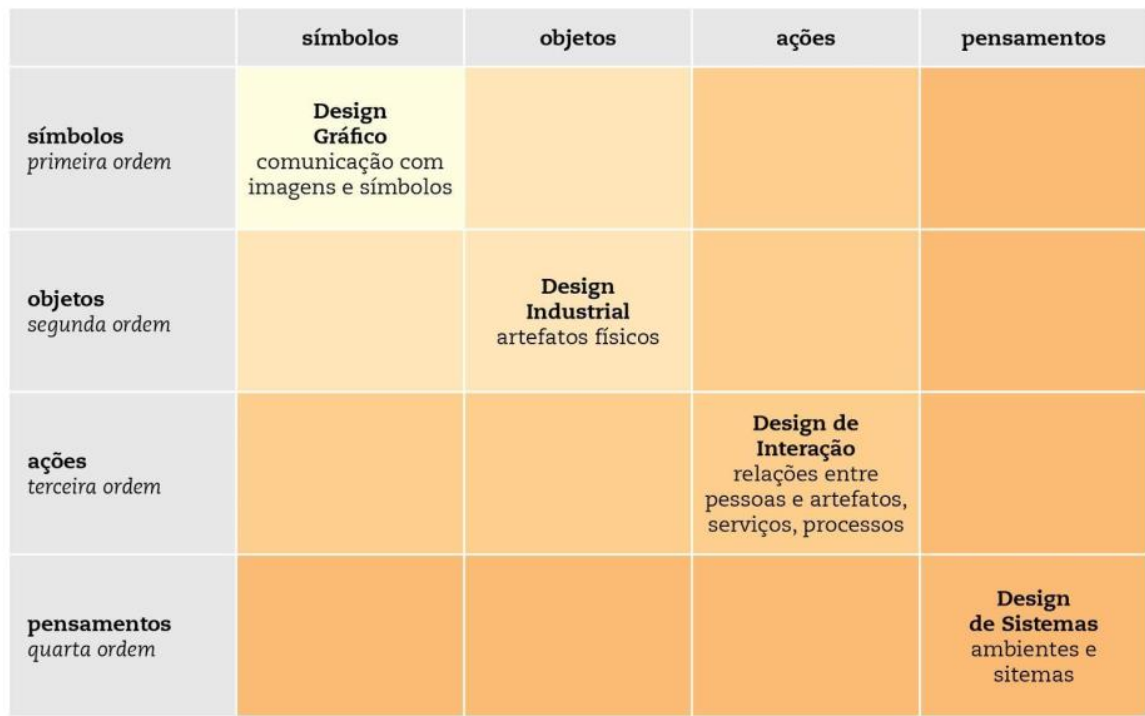

Figura SEQ Figure 1* ARABIC 1: As quatro ordens do design. Fonte: dos autores, 2020. Adaptado de Buchanan (2001, p.12).

A ideia é que as "imagens, símbolos ou coisas", da primeira e segunda ordem, precisam se tornar parte de uma experiência humana, ligadas à "ação e ao ambiente", de terceira e quarta ordem, interferindo nas experiências de forma significativa. Como o próprio autor reconhece, a abordagem sistêmica não é novidade, identificando esse tipo de reflexão nos projetos desde o século XIX. Seu argumento é de que a própria definição de sistema se tornou mais elaborada, de sistema de "coisas" para sistemas "humanos" (BUCHANAN, 2001, p.11). Apesar de existir a possibilidade de um entendimento hierárquico valorativo entre os níveis apresentados por Buchanan (ex. um nível "melhor" que outro), ela não é uma classificação estanque.

O autor afirma que o design está cada vez mais relacionado à solução de projetos que envolvem temas amplos - ou capciosos -, como o da educação, considerando a esfera social e política de forma mais explícita. É uma argumentação que extrapola uma abordagem excessivamente conservadora da finalidade da prática do design, cuja ênfase está normalmente em identificar uma metodologia de projeto generalizada em processos de manufatura, análises de mercado, etc., não obstante todas essas questões também sejam importantes. Ela revela o potencial do design como uma área onde é possível realizar a integração de diversos saberes (BUCHANAN, 2001, p.0607), reconhecendo suas contribuições diante da corrente expansão do campo projetual. O evento 
que propusemos se funda nesta visão sistêmica, considerando as abordagens do Design de Transições e Prospectivo, conforme veremos na próxima seção.

\section{Design de Transições e Design Prospectivo}

As mudanças climáticas e ambientais que nos acometem são consequência das contradições e limitações das epistemologias, metodologias e ontologias da nossa sociedade. Tais contradições resultam da dissociação entre nossos sistemas sócio-técnicos (conjunto de sistemas, práticas, técnicas, tecnologias, artefatos, etc. que permeiam o nosso cotidiano) e os sistemas naturais de onde emergem. Todo sistema sócio-técnico se funda numa rede composta por diversos elementos e agentes muitas vezes concorrentes, o que gera "problemas capciosos", como as mudanças climáticas. Estes, quando emergem, não podem ser resolvidos por ações pontuais independentes de reflexões amplas em escala espacial e temporal: exigem ações, justamente, sistêmicas. A pandemia COVID-19 é um problema desta espécie, por ter origem em diversos fatores interligados, consequentes de um modelo de sociabilidade e de técnicas que precisam ser adaptadas, sob o risco de nos depararmos com consequências cada vez mais trágicas.

A disciplina do Design tem passado por transformações marcadas pela consciência de que tais "problemas capciosos" estão inter-relacionados em múltiplas escalas, e pelo reconhecimento que designers detêm saberes que os capacitam lidar com eles. Também é sinal do nosso tempo a apropriação dos métodos e ferramentas do Design por outras áreas (BUCHANAN, 2001). Neste contexto, nasceram e se consolidaram o Design para Serviços e Design para Inovação Social, duas abordagens relacionadas a tais transformações. Uma terceira abordagem, complementar e consequente destas duas, é descrita por Terry Irwin, diretora da Escola de Design da Universidade Carnegie Mellon, no artigo intitulado 'Transition Design: A Proposal for a New Area of Design Practice, Study, and Research' (2015). Nele, a pesquisadora propõe a urgência da prática do Design de Transições, que se funda na urgência de adotarmos uma visão de longo prazo, e no reconhecimento da necessidade de lermos e propormos respostas de Design ancoradas em paradigmas mais sustentáveis. As ferramentas e métodos desta abordagem servem à formulação de visões especulativas baseadas no local e no reconhecimento do mundo natural como o contexto-base para as respostas de Design. Tais visões servem para inspirar, informar e orientar o projeto de soluções de curto e médio prazo, de modo que se desenvolva uma mudança gradual, até que se chegue no ponto de substituição de um sistema sócio-técnico por outro (GEELS, 2005; IRWIN, 2015). Estas três abordagens permeiam a terceira e a quarta ordem de design propostas por Buchanan $(1992,2001)$.

Para Irwin, a relação entre Design de Serviços, Design para Inovação Social e Design de Transições é de continuidade espaço-temporal. Sua escala cresce no tempo, na profundidade do engajamento, mas também no contexto, para incluir preocupações ambientais e sociais e, sobretudo, para questionar paradigmas. Enquanto o Design de Serviços utiliza uma abordagem sistêmica, para deslocar sua atenção dos artefatos para as interações e experiências entre clientes e provedores de serviços, o Design para Inovação Social se distancia do contexto estrito das relações comerciais, para atuar em paradigmas emergentes e modelos econômicos alternativos, 
buscando mudanças sociais positivas e significativas. Por sua vez, o Design de Transições se coloca não só como questionador, mas como propositor de novos paradigmas, apoiado na interdependência e conexão entre os sistemas políticos, sociais, econômicos, culturais e naturais. O continuum que liga os três níveis de Design, a que se refere a autora, se consolida com a ideia de que as perspectivas de transição podem oferecer um recurso para projetos desenvolvidos nos setores de Serviços e Inovação Social, conectando-os em rede e formando-os para construir etapas transitórias mais inteligentes e inter-relacionadas. Assim, a visão de longo prazo orienta a construção dos marcos de curto prazo que são posicionados ao longo de um "caminho de transição", formado pela retransmissão da visão futura para o presente (IRWIN, 2015).

Uma das propostas associadas a este mesmo movimento é o Design Prospectivo (ENGELER, 2017). Enquanto campo teórico, apresenta uma maneira de pensar e transformar gradualmente a realidade. Enquanto campo prático, consolida as competências de prospecção, antecipação, facilitação, articulação, integração e transformação que designers profissionais têm desenvolvido a partir da sua atuação na sociedade nas últimas décadas. Esta abordagem se baseia na análise dos sistemas sócio-técnicos e da relação entre seus componentes para alimentar estudos exploratórios, num processo projetual que visa criar cenários futuros e suas transições num intervalo de tempo (BROWN e KATZ, 2009).

\section{Visão de Design em construção pelo grupo de estudos e pesquisas em Design Prospectivo} da UTFPR

Entendemos que os saberes projetuais são indispensáveis para lidar com os chamados "problemas capciosos". A presente pandemia coloca em evidência a necessidade de transicionarmos para um modo de vida mais sustentável, igualitário, justo do ponto de vista econômico, social, político, consonante com a nossa realidade latino americana.

Isto posto, estamos trabalhando na decolonização das propostas do Design de Transições e Prospectivo para propor uma abordagem prospectiva que ancoramos no conceito das Epistemologias do $\mathrm{Sul}^{5}$, proposto por Boaventura de Sousa Santos (SANTOS, 2019). O conceito se funda na ideia que a experiência colonial moderna reforça a divisão do mundo em zonas coloniais e metropolitanas, e que tal divisão se mantém através da colonialidade do saber e do pensamento abissal, que esconde relações colônia-metrópole. Encontramos uma intenção similar em Arturo Escobar, com sua proposição do conceito de Transiciones (ESCOBAR, 2015). Entendemos que as teorias que importamos das metrópoles devem ser acolhidas criticamente, não só adaptadas à nossa realidade e às nossas visões-de-mundo, mas que devemos nos tornar sujeitos de saber a partir das nossas experiências, história, sociabilidades, culturas e assim por diante, para conseguirmos entender as transformações de que necessitamos. Ao buscar uma visão holística,

\footnotetext{
5 “As Epistemologias do Sul se assentam em três orientações: aprender que existe o Sul; aprender a ir para o Sul; aprender a partir do Sul e com o Sul.” (SANTOS, 1995; 2019).
} 
precisamos considerar que um sistema sócio-técnico local se relaciona intimamente a um sistema maior, global, marcado por relações específicas.

Assim, nossa abordagem do Design Prospectivo se interessa por: a) buscar rigor nas pesquisas científicas para ampliar o campo de intervenção do Design; b) refletir criticamente sobre a relevância e a legitimidade dos saberes desenvolvidos na sua prática; c) refletir ética e afetivamente sobre os impactos das intervenções de Design nos ambientes e agentes que atingem; d) reconstruir uma epistemologia de Design condizente com a perspectiva latino-americana; e) construir e manter pontes interdisciplinares; f) inserir econômica, social, cultural e politicamente as figuras de pesquisadores e profissionais do Design; g) interseccionar teoria e prática no desenvolvimento de projetos prospectivos significativos e impactantes em pequena, média e grande escala, visando o resultado a longo prazo.

Como veremos, nos orientamos pelos conceitos do Design de Transições e do Design Prospectivo para a construção de um evento prospectivo, um metaprojeto do futuro da UTFPR.

\section{Organização do evento-piloto}

Contexto, motivação e notas sobre a organização deste metaprojeto

Quando o Diretor-geral da OMS, Tedros Ghebreyesus, declarou o COVID-19 estado de pandemia em 11 de março de 2020, as aulas da UTFPR foram suspensas, sem previsão de retorno. Logo, o corpo docente da universidade começou a organizar seus esforços em torno de projetos de extensão, grupos de discussão e pesquisa para amenizar o impacto causado pela crise. Enxergamos a oportunidade de exercer nosso papel social aplicando nossa visão do Design Prospectivo, já que desenvolver estratégias projetuais para planejar transições de grande impacto e visando o longo prazo se mostrou não só atual como urgente.

Primeiramente, investigamos respostas do Design no âmbito internacional para alimentar um mapeamento do espaço projetual da crise COVID- $19^{6}$. Com esta pesquisa constatamos que a grande maioria dos projetos propunham artefatos e objetos materiais de serventia emergencial ou paliativa, como máscaras, barreiras de isolamento e ventiladores mecânicos. Outras, em menor quantidade, se destinavam a protocolos de segurança para convívio social, soluções situadas entre a primeira e terceira ordens do Design descritas por Buchanan (2001). Ainda que reconheçamos que todos estes produtos são imprescindíveis para resolver questões em curtíssimo prazo, não encontramos soluções projetuais que buscassem resolver problemas sistêmicos da quarta ordem, articulando as várias partes de um sistema sócio-técnico. No máximo, encontramos problematizações. Nossa hipótese a respeito da viabilidade de praticarmos e ensinarmos design visando o planejamento para médio e longo prazo nos pareceu fraca. Por isso, decidimos propor um exercício relâmpago como ferramenta para angariar respostas e problematizações que considerassem a abordagem prospectiva, convocando profissionais, docentes e estudantes de

\footnotetext{
${ }^{6}$ Para acessar o mapeamento das controvérsias e do espaço projetual das respostas do Design à crise do COVID-19 realizado por docentes do grupo de estudos e pesquisas em Design Prospectivo, acesse este link: kumu.io/usabilidoido/covid-19-design-responses\#design-responses
} 
áreas cuja atuação se baseasse em projetos para pensarem o futuro da UTFPR, visando o ano de 2050.

O exercício que propusemos se baseia no modelo Charrette, prática originária da École des Beaux-Arts de Paris do século XIX, ainda frequentemente empregada na comunidade acadêmica de arquitetura e das artes. Na Charrette, um problema prático é lançado e deve ser resolvido em curto período de tempo (LENNERTZ; LUTZENHISER, 2006). Na área de Design, existe um exercício semelhante à Charrette, chamada Repentina. Seu nome, cunhado pelo Prof. Ivens Fontoura, é inspirado no cancioneiro repentista, cuja manifestação artística consiste em, de improviso, responder às provocações de seu oponente por meio do canto. A prática da Repentina nasce, então, como uma oportunidade de propor uma resposta projetual rápida, co-criativa e interativa a um problema ou sobre um tema.

Da união da teoria do Design Prospectivo com a modalidade da Repentina nasceu a Prospectina, como ação de extensão universitária, um metaprojeto que visa:

1. Divulgar o Design Prospectivo como uma abordagem urgente, e emergente no Departamento de Desenho Industrial da UTFPR;

2. Experimentar a abordagem prospectiva e as práticas transicionais;

3. Problematizar as questões do ensino universitário brasileiro, em particular, a relação entre universidade e comunidade;

4. Permitir que docentes, estudantes e comunidade trabalhassem em conjunto, considerando a importância de cada agente na problematização e proposição de soluções aos problemas da educação na UTFPR, visando o longo prazo;

5. Captar conteúdo reflexivo sobre o futuro da UTFPR para direcionar à Reitoria da Universidade, com o intuito de manifestar e legitimar opiniões e necessidades das comunidades interna e externa.

\section{Como nossa visão do Design Prospectivo nos orientou na criação de cenários?}

Segundo Bridgette Engeler, os cenários são um meio de desenvolver e explorar alternativas futuras, um ponto de chegada a vislumbrarmos no decorrer do trabalho, que nos auxilia a pensar em resultados futuros. Eles podem ser otimistas ou ideais, pessimistas ou distópicos, podem ser desastrosos e não muito diferentes do presente. Podem considerar questões que se referem ao modo como as pessoas se engajam, interagem entre si e com o ambiente, quais agentes estarão presentes neste futuro e que papel podem desempenhar, ou ainda, quem serão as pessoas privilegiadas nas condições apresentadas (ENGELER, 2017).

Para conduzir o trabalho das equipes, propusemos quatro cenários futuros, acompanhados de perguntas instigantes, que idealizamos com inspiração em um workshop para educadores em 
Design $^{7}$. Devido ao curto intervalo de tempo, entendemos que a proposta foi encaminhada de forma a promover as práticas prospectivas almejadas, ainda que o debate de seus aspectos teóricos não tenham sido aprofundados durante a atividade. Sugerimos às equipes que explorassem esses cenários ou criassem outros a partir de suas próprias reflexões e realidades. Os cenários apresentados foram:

\section{1. "Tão Longe, tão perto"}

Com a pandemia COVID-19, possivelmente, a UTFPR, assim como outras IES, terá de se adaptar a uma política pedagógica de ensino remoto $^{8}$. Alguns dos muitos problemas que esta modalidade de aprendizagem suscita são extremamente capciosos.

- Para que serve o ambiente coletivo que o ensino presencial nos proporciona?

- Como e o que avaliar, e certificar na modalidade?

- Quais mudanças são viáveis, quais são inviáveis, e quais são desejáveis?

- Como resolver remotamente a transferência de saberes que hoje acontecem em laboratórios, estúdios e oficinas?

- Quais as implicações da possível assincronia espaço-temporal do ensino remoto?

\section{2. "Educação (não) é mercadoria?"9}

O Ensino superior público no Brasil vem sofrendo cortes e ataques. A universidade vem tendo sua autonomia, independência, capacidade de pesquisa e atuação social tolhidas. A pandemia evidenciou e exacerbou estes cortes de investimentos e capacidade de ação.

- Como a produção de conhecimentos 'não-rentáveis', do ponto de vista mercadológico, se legitimará?

- Como a universidade se sustentará?

- O que a pandemia nos evidencia, e o que possivelmente nos dirá, a respeito do papel das universidades públicas para a soberania nacional?

- Quais impactos nossa universidade pública pode ter na construção efetiva da justiça social no Paraná, no Brasil?

\footnotetext{
${ }^{7} \mathrm{O}$ workshop Envisioning Futures of Design Education: An Exploratory Workshop with Design Educators para educadores em Design aconteceu na Design Research Society em Brighton, Reino Unido. (SINGH. et. al., 2018).

${ }^{8} \mathrm{O}$ termo ensino remoto foi adotado pela Reitoria da UTFPR nas portarias e memorandos que redigem para guiar o planejamento docente. Entendemos como eufemismo para Educação à Distância, uma modalidade pedagógica que tem seu valor, mas é marcada por diversas limitações, e não pode ser substituta do Ensino Presencial, mas complementá-lo.

${ }^{9}$ A ironia implícita neste título vem da citação do conhecido e potente 'grito de guerra', presente nas manifestações de rua contra os cortes de investimentos governamentais na educação pública desde 2016: Se você paga, não deveria: educação não é mercadoria. A palavra 'não' entre parênteses e a interrogação ao final da frase denunciam a situação de incerteza, e a costumeira conformação que marca nosso inconsciente coletivo enquanto colônia.
} 


\section{3. "Tecnologias locais para lutas globais"}

Este cenário considera que toda tecnologia surge de uma intenção e carrega consigo um viés, uma tendência a facilitar certos usos. Esse viés pode oprimir ou libertar pessoas, porém, isso nem sempre está claro. Para que o viés seja claramente libertador, é preciso primeiro ter o domínio da tecnologia no nível local, para compreender suas intenções e possibilidades. Uma vez apropriada, a tecnologia pode ser usada para apoiar lutas globais contra a opressão, como por exemplo a educação bancária, que atinge escala planetária com os Massive Open Online Courses (MOOC).

- Como a educação aliada às tecnologias libertadoras podem contribuir para uma cidade, um país, um mundo mais humanizado?

- Como materializar intenções libertadoras em tecnologias voltadas para a educação?

4. "Educação para um mundo onde caibam vários mundos"

A universidade não precisa ser um agente de padronização do conhecimento e eliminação da diferença cultural. A universidade pode e deve reconhecer os conhecimentos que surgem das diversas ciências e disciplinas acadêmicas, assim como das tradições ancestrais e práticas artesanais, sem estabelecer hierarquias ou julgamentos de valor. A educação pelo diálogo pode promover a criação de conhecimentos híbridos que permitem a existência de diversos mundos dentro de um só. A pluriversalidade oferece caminhos possíveis para a convivência solidária em contextos de diferença e desigualdade.

- Como a diversidade pode ser realmente incorporada na UTFPR e que impactos ela terá em 2050 ?

- Que outros saberes além do científico já são cultivados pela universidade tecnológica?

- Como a universidade pode contribuir para a pluriversalidade?

Os cenários que propusemos trazem acenos ao arcabouço teórico da visão prospectiva que estamos construindo. O primeiro deles é o conceito de 'problemas capciosos', que perpassa todos os quatro cenários.

Todos eles se constituem como indicações de perspectivas de médio a longo prazo, apontando direções ambíguas e controversas. Mostram que é possível que uma só decisão de grande impacto pode transformar drasticamente nossa realidade, e motivam participantes a explorar estes futuros possíveis.

Os cenários \#3 e \#4 se articulam dentro da perspectiva decolonial, e propõem uma reflexão acerca do paradigma científico e do ensino superior. Enquanto o cenário \#3 propõe a problematização e expansão do campo prospectivo no que se refere à educação libertadora, o \#4 fala da inclusão de pessoas, ideias, ontologias, saberes, para a transição para uma universidade plural. Estes cenários evidenciam a intencionalidade política do Design Prospectivo. 


\section{Reflexões sobre os resultados da repentina}

O evento contou com a participação de estudantes orientados por docentes do DADIN, e também de uma equipe formada por um professor do ensino médio e seus estudantes, além de discentes de outros cursos. Estimulamos que aplicassem as ferramentas representativas, métodos e abordagens projetuais que lhes parecessem adequadas para que delineassem representações de futuros para a UTFPR no ano de 2050.

Os oito novos conceitos gerados pelas equipes foram apresentados com o uso de diversas ferramentas e linguagens representativas (fanzines, relatórios, cronogramas e contos literários). Essa variedade revelou um grande conjunto de possibilidades de linguagens e estratégias projetuais para serem utilizadas como suporte e mediadoras de discussões complexas. Após a entrega dos trabalhos, houve um encontro virtual entre os participantes, que compartilharam suas experiências, motivações e abordagens escolhidas, reforçando o caráter colaborativo do processo como um todo.

Foi possível identificar que muitas das propostas evidenciam a visão decolonial de que as universidades devem se transformar em "pluriversidades", acomodando diversas visões de mundo e tipos de saberes. As observações, demandas e proposições que emergiram delas revelam que urgem novas relações internas horizontais e práticas colaborativas entre comunidade e universidade, assim como a integração entre universidades federais em termos de infraestruturas e outras formas de cooperação, que poderiam ser facilitados pelas novas tecnologias. Além disso, diálogos transdisciplinares devem se expandir de maneira mais organizada, visando a instauração de uma educação contextualizada e libertadora. Destacamos também a preocupação recorrente com a destinação dos recursos financeiros e sua relação com a autonomia universitária, docente e estudantil.

A partir da Prospectina, reafirmamos a importância da universidade nos processos de transformação social. Um Projeto de Extensão Universitária foi concebido visando propor transições efetivas para a adaptação da UTFPR à realidade pós-pandemia. Seus resultados serão encaminhados à Reitoria da Universidade com a finalidade de fornecer perspectivas abertas para planejar o futuro de nossa instituição. As diversas propostas apontam caminhos criativos e sensíveis à complexidade dos inúmeros contextos presentes no cotidiano dos participantes. Destacamos que são resultados de um processo colaborativo e focado em metodologias próprias do design. Entendemos que essa experiência poderá gerar percepções importantes sobre a decolonialidade no design e na educação, evidenciando seus potenciais críticos e transformadores.

\section{Conclusões}

Observamos que o Design Prospectivo foi fundamental na definição da modalidade e na elaboração dos objetivos deste metaprojeto, pois o direcionamento que a teoria propôs contribuiu para o engajamento da comunidade sobretudo na problematização da situação da educação superior brasileira. 
Entendemos que a riqueza das respostas projetuais é devida ao potencial do Design Prospectivo em fornecer significado, ao mesmo tempo que orientações pragmáticas a projetistas que se engajam nesta abordagem. A mesma segurança que obtivemos para sistematizar os cenários que propusemos, com apoio neste arcabouço teórico, foi sentida pelas equipes participantes. Consideramos que as sugestões dos cenários ajudaram-nas a encontrar um ponto de partida mais rico e provocador, estendendo os limites dos seus questionamentos e interpretações da realidade.

Acreditamos que isto decorre do fato de reconhecermos o nosso espaço projetual como um campo sistêmico, dependente de contextos complexos e criador de vieses, dotado de uma dimensão política e de objetivos abrangentes que não só podem, mas devem ser definidas. Saber que podemos, primeiramente, enxergar os problemas sobre os quais agir de maneira sistêmica, para depois trabalharmos sobre eles de maneira pragmática, com ferramentas e saberes únicos, não só confere significado à nossa prática, como revela o enorme potencial e relevância da nossa rica - e capciosa - área de atuação. A Prospectina nos mostrou que tal expansão do espaço projetual é o contributo mais importante da práxis prospectiva para nós.

\section{Referências}

ANDIFES. Associação Nacional dos Dirigentes das Instituições de Federais de Ensino Superior. V Pesquisa Nacional de Perfil Socioeconômico e Cultural dos (as) Graduandos (as) das IFES - 2018. Brasília, 2019. Disponível em <http://www.andifes.org.br/wpcontent/uploads/2019/05/V-Pesquisa-Nacional-de-Perfil-Socioecon\%C3\%B4mico-eCultural-dos-as-Graduandos-as-das-IFES-2018.pdf>. Acesso em 10 de maio de 2020.

BOTERO, Andrea; KOMMONEN, Kari-Hans \& MARTILLA, Sanna. Expanding Design Space. Design-in-Use Activities and Strategies, Proceedings of the DRS 2010 Conference: Design and Complexity. Montreal, 2010.

BROWN, Tim. e Katz, Barry. Change by Design: How Design Thinking Can Transform Organizations and Inspire Innovation, New York, Harper Collins Business, 2009.

BUCHANAN, Richard. Wicked Problems in Design Thinking. Design Issues, Cambridge, MIT Press, vol. 8, no. 2, 5-21. 1992.

BUCHANAN, Richard. Design research and the new learning. Design Issues, Cambridge, MIT Press, Vol. 17, no. 4, 3-23. 2001.

CHIEN, Sheng-Fen e FLEMMING, Ulrich. Design space navigation in generative design systems. Automation in Construction 11, 1-22. 2002.

ENGELER, Bridgette. Towards prospective design, The Design Journal, 20:sup1, S4591S4599, 2017. DOI: 10.1080/14606925.2017.1352956.

ESCOBAR, Arturo. Transiciones: a space for research and design for transitions to the pluriverse. Design Philosophy Papers, VOL. 13, NO. 1, 13-23, Routledge, 2015. DOI:10.1080/14487136.2015.1085690

FEENBERG, Andrew. The Online Education Controversy and the Future of the University. Foundations of Science, dezembro de 2015. DOI: 10.1007/s10699-015-9444-9

GEELS, Frank W. The Dynamics of Transitions in Socio-technical Systems: A Multi-level Analysis of the Transition Pathway from Horse-drawn Carriages to Automobiles (18601930), Technology Analysis \& Strategic Management Vol. 17, No. 4, 445-476. Routledge. 2005. 
GOLDSCHMIDT, Gabriela. Capturing indeterminism: representation in the design problem space. Design Studies 18, 441-445. 1997.

IRWIN, Terry. Transition design: a proposal for a new area of design practice, study, and research. Design and Culture, Londres, v. 7, n. 2, 229-246. 2015.

KEES, Dorst E CROSS, Nigel. Creativity in the design process: co-evolution of problemsolution. Design Studies, 22(5), 425-437. 2001.

LENNERTZ Bill. e LUTZENHISER, Aarin. The Charrette handbook: The Essencial Guide to Design-Based Public Involvement. Routledge. 2017.

RITTEL, Horst W. On the Planning Crisis : Systems Analysis of the 'First and Second Generations'. Bedriftsf Konomen nr.8 390-396, $197 .$.

SANTOS, Boaventura de Sousa, Toward a New Common Sense: Law, Science and Politics in the Paradigmatic Transition. New York: Routledge, 1995.

SANTOS, Boaventura de Sousa (ed.). O Fim do Império Cognitivo: a afirmação das Epistemologias do Sul. 1 edição, Autêntica Editora: Belo Horizonte, 2019.

SINGH, Nicole LOTZ e SANDERS, Elizabeth B.-N. Envisioning Futures of Design Education: an Exploratory Design Workshop with Design Educators, Dialectics 2.1, 19-46, 2018.

WESTERLUND, Bo. Design space conceptual tool - grasping the design process. Proceedings for 'In the Making', Nordes, the Nordic Design Research Conference, Copenhagen, Denmark. 2005.

\section{Sobre os autores}

\section{Fernanda Botter}

Doutora em 'Composizione Architettonica' pelo Politecnico di Milano (2014) IAUUSP (2015). Possui graduação em Arquitetura e Urbanismo pela UFPR (2006). Atualmente é professora Adjunta dos Cursos de Bacharelado em Design e de Tecnologia em Design Gráfico da UTFPR. É pesquisadora na área de Design Prospectivo e membro do Grupo de Estudos e Pesquisas em Design Prospectivo na mesma instituição.

fernandabotter@utfpr.edu.br

\section{Kando Fukushima}

Bacharel em Desenho Industrial com habilitação em Programação Visual pela UFPR, especialista em História da Arte do século XX pela Escola de Música e Belas Artes do Paraná (EMBAP) e mestre e doutor em Tecnologia e Sociedade (UTFPR). Atualmente é professor Adjunto do Departamento Acadêmico de Desenho Industrial da UTFPR. Pesquisador na área de Design e membro do Grupo de Pesquisa Design e Cultura / UTFPR.

kando@utfpr.edu.br

\section{Milena Maria Rodege Gogola}

Possui Especialização em Design de Embalagem - Projeto e Produção pela UTFPR, graduação em Desenho Industrial - Projeto de Produto pela PUCPR (2004) e em Programação Visual pela PUCPR (2007). Atualmente é professora substituta na UTFPR nos Cursos de Bacharelado em Design e de Tecnologia em Design Gráfico, é membro do grupo de estudos e pesquisas sobre Design Prospectivo na mesma instituição. milenamrg@gmail.com 